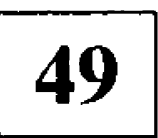

\title{
INVESTIGATING MULTILEVEL RELATIONSHIPS IN VIRTUAL TEAMS: AN ILLUSTRATION USING HIERARCHICAL LINEAR MODELING
}

\author{
Gabriele Piccoli \\ School of Hotel Administration, Cornell University, gp45@cornell.edu \\ USA \\ Jeremy Short \\ School of Business Administration, Portland State University, jeremys@sba.pdx.edu \\ USA \\ Blake Ives \\ C.T. Bauer College of Business, University of Houston, bives@acm.org
}

USA

\begin{abstract}
Virtual teams are inherently hierarchical entities involving individual team members within teams. Previous work has yet to fully engage their multilevel theoretical nature. In this article we introduce Hierarchical Linear Modeling (HLM) as a statistical tool that can appropriately test cross-level relationships and model the multilevel nature of virtual team phenomena. Using data from a study involving 51 virtual teams, we illustrate the advantages of HLM over altemative approaches. Our results show that significant variance in individual satisfaction with a virtual team experience exists both within and between groups and that the individual perception of communication effectiveness is a significant predictor of satisfaction. Our results also demonstrate a significant main effect of team coordination, a team-level construct, on individual satisfaction.
\end{abstract}

\section{INTRODUCTION}

The extraordinary development of Information Technologies (IT) in the last two decades has been critical in supporting the development of new organizational forms (Jarvenpaa and Ives 1994). As businesses strive to respond to competitive pressure and seek to improve their flexibility, they increasingly turn to the use of virtual teams (Townsend, DeMarie and Hendrickson 1998). Virtual teams are groups of geographically, temporally, and/or organizationally dispersed knowledge workers brought together across time and space via information and telecommunication technologies (DeSanctis and Poole 1997; Jarvenpaa and Leidner 1999; Lipnack and Stamps 1997). Recognizing the potential benefits (Lipnack and Stamps 1997;

The original version of this chapter was revised: The copyright line was incorrect. This has been corrected. The Erratum to this chapter is available at DOI: 10.1007/978-0-387-35585-6_68 
Townsend et al. 1998) and risks (Duarte and Snyder 1999) that the introduction of virtual teams engender, Information Systems (IS) researchers have recently begun their systematic study.

As IS research on virtual teams grows rapidly, it is important to address the theoretical and methodological implications of their multilevel nature. Current approaches do not offer an optimal methodology to analyze the cross-level relationships inherent in virtual team research. This is unfortunate because modeling and understanding the interplay of team and individual-level variables is a necessary prerequisite to fully comprehend virtual team dynamics. We illustrate the explicit investigation of multilevel relationships in virtual teams by providing an illustration set in the context of a study of individual satisfaction with the virtual team experience, and we use Hierarchical Linear Modeling (HLM) to appropriately test cross-level main effects and interaction effects to improve our understanding of the individual-level and team-level determinants of team members' satisfaction with a virtual team experience.

\section{THE CROSS-LEVEL NATURE OF VIRTUAL TEAM RESEARCH}

Virtual teams are intrinsically hierarchical entities involving the situated nature of team members within groups. Thus, virtual team research is inherently cross-level and is concerned with the interplay of context and behavior in context. Cross-level research examines "the effect of variables at one level [of analysis] on those at another" (Rousseau 1985 p. 2). For example, several studies have compared virtual teams using different portfolios of communication technologies (Galegher and Kraut 1994). Given the inherent cross-level nature of virtual teams, a "meso" level paradigm (House, Rousseau and Thomas-Hunt 1995) is most appropriate to their investigation. Meso level research is defined as inquiry that "examines the relationship between organizational contexts and behavior of components (individuals, dyads, groups, organizations, and groups of organizations) and evaluates how those relationships shape outcomes" (House et al. 1995 p. 85). A meso approach to virtual team research requires that our theories include both individual-level and team-level (contextual) variables, and that we adopt appropriate analytical techniques.

Individuals' satisfaction with their teamwork experience has received attention in both the traditional team literature (Guzzo and Dickson 1996) as well as the virtual team literature (Furst, Blackburn and Rosen 1999). Previous research suggests that both individual characteristics and individual perceptions are important determinants of individual satisfaction (Galegher and Kraut 1994), and that the social context developing within teams as they perform influences team members' attitudes and behaviors (Hackman 1992). Such social context is shaped by the characteristics of the individuals involved, the organizational environment in which the team is embedded, the technology available to the team and how it is appropriated. A different social context emerges in different teams, and its effect should be reflected in different individual responses within the teams. Thus, 
H1: Significant variance in individual satisfaction with the team experience exists both within and between virtual teams.

Previous research in virtual teams has focused on individual perceptions of group processes and their effect on individual outcomes such as members' satisfaction or commitment. This literature reports a direct positive relationship between individual perception of group processes and individual-level outcomes; however, an explicit empirical link between individual perceptions of communication effectiveness and satisfaction has yet to be established. We suggest that in the virtual environment, where communication is both a significant challenge (Walther 1995) and the most available source of visible action by team members (Galegher and Kraut 1994), individuals will report high satisfaction with their virtual team experience when they perceive their communication interaction with teammates to be highly accurate, timely and useful. Therefore,

H2: Individual perceptions of communication effectiveness are positively related to individual satisfaction with the virtual team experience.

Team coordination is a team-level construct that represents the extent to which the team is able to work on the project without major failures, in concert, and without redundancy of effort. Highly coordinated teams tend to have a clear sense of direction and their members work coherently, knowing their role and what is expected of them. A high level of coordination among team members is generally regarded as a characteristic of effective co-located teams (Pinto, Pinto and Prescott 1993). Coordination difficulties represent a major hurdle faced by co-located project teams, and arise from dependencies between team members. In the virtual environment, the inability to meet face-to-face appears to further impair effective coordination (Jarvenpaa and Leidner 1999; Jarvenpaa, Knoll and Leidner 1998). High team coordination creates a context where team members can productively and complementarily contribute to a project. Thus,

H3: Team coordination is positively related to individual satisfaction with the virtual team experience.

Early virtual team research indicates that the virtual context considerably increases task uncertainty and the need for extensive communication (Jarvenpaa and Leidner 1999; Jarvenpaa et al. 1998). Successful virtual teams tend to engage in extensive and predictable communication patterns (Jarvenpaa and Leidner 1999; Jarvenpaa et al. 1998). These findings suggest that extensive communication is positively related to team effectiveness and individual satisfaction. But in the virtual context, the extent to which team members communicate is partly determined by idiosyncratic work processes and by difficulties each team may encounter during the project (Piccoli and Ives 2001). For example, a team may organize itself in subgroups, drastically reducing the need for coordination. Alternatively, its members may have highly conflicting schedules that require extensive communication simply to find a suitable time to meet (Piccoli and Ives 2001). The amount of communication within a team may moderate the relationship between perceived communication effectiveness and satisfaction. When individual members of a team that communicates extensively perceive communication to be ineffective, feelings of frustration and overload lead to lower satisfaction with the virtual team experience. 
Conversely, when members of a team that exchange few messages perceive communication to be effective, they report high satisfaction as the team experience is regarded as very efficient. Stated formally,

H4: Team communication quantity moderates the relationship between individual communication effectiveness and satisfaction with team experience.

\section{SAMPLE AND MEASURES}

201 students from five business schools in the US, Europe and New Zealand were randomly assigned to teams so that no two team members could be co-located. 51 teams of three and four members took part in the study. The project consisted of the development of a business plan for a new Internet-enabled venture, and was consistent with projects used in similar studies (Jarvenpaa and Leidner 1999). This project is particularly well-suited for virtual team research because it requires considerable interaction among teammates and has components of decision-making, idea development, and information exchange. The project also requires the extensive communication and coordination typical of virtual team efforts (Furst et al. 1999). A substantial portion of students's final course grade (20-25\%) depended on their team's project performance.

Satisfaction, defined as the degree to which the individual feels that the team experience has been personally rewarding, was measured using five-items from a validated instrument by Pinto and colleagues (1993). An example item is "I am very proud of the business plan project." Individual perceptions of communication effectiveness, defined as the individual evaluation of the extent to which information exchanged by team members is timely, useful and reliable, was measured using a validated three-item instrument (Frone and Major 1988). Team coordination represents "the extent to which the work activities of organizational members are logically consistent and coherent." (Cheng 1983 p. 156). Team coordination measures how organized the team is in carrying out its mission and whether work activities are complementary and directed toward a common goal without duplication of effort or fragmentation. The coordination scale was based on a modified five-item, scale (Janz et al. 1997) with representative items such as: "My team had a clear sense of direction during the project." We conceptualize team coordination as a team level variable and measured it by way of individual team members' assessments. Individual responses where aggregated into team-level measures. Team communication quantity represents the amount of communication exchanged by the team members, and we used the total number of email messages as a measure of communication quantity.

\section{HIERARCHICAL LINEAR MODELING}

Hierarchical Linear Modeling (HLM) provides a tool to appropriately conceptualize and test the cross-level relationships hypothesized above. HLM separates individual level variables and team level variables by specifying distinct level-1 and level-2 models. Although HLM is presented as a system of equations, estimation is simultaneous; simultaneous estimation techniques improve upon ANOVA or 
variance components approaches by using fewer degrees of freedom, thereby providing better estimates (Bryk and Raudenbush 1992).

The first level examines relationships among variables within virtual teams that generate intercept and slope parameters linking the within-team independent variable (i.e., perceived communication effectiveness) to the outcome measure for each team (i.e., individual satisfaction). This model is analogous to OLS regression, although the Bayes algorithm used to estimate the level-1 components is noted for its superior precision and reliability (Bryk and Raudenbush 1992). In the level-2 model, the intercept and slope parameters are used as outcome variables and regressed on between-team variables.

When estimated without predictor variables, the level-2 model is essentially a one-way analysis of variance (Hofmann 1997). The HLM ANOVA model is used to test hypothesis 1 . This is accomplished by partitioning variance into within (i.e., individual-level) and between (i.e., team-level) team components (cf. Bryk and Raudenbush 1992; Hofmann 1997). The following set of equations is estimated to conduct the variance partitioning:

Level-1: $\quad$ Satisfaction $_{i j}=\beta_{0 j}+r_{i j}$

Level-2: $\quad \beta_{0 j}=\gamma_{00}+U_{0 j}$

Where Satisfaction ${ }_{i j}$ represents individual satisfaction with the virtual team experience expressed by individual $i$ in team $j . \beta_{0 j}$ is the mean satisfaction for team $j$, and $\gamma_{00}$ is the grand mean satisfaction (i.e., the mean of team means). In this set of equations, the level-1 equation includes no predictors and, as a consequence, the regression equation only includes an intercept estimate. The level-2 model regresses mean satisfaction scores of each virtual team onto a constant; that is, $\beta_{0 j}$ is regressed onto a unit vector resulting in a $\gamma_{00}$ parameter equal to the grand mean satisfaction (i.e., the mean of team means, $\beta_{0_{j}}$ ). The level-1 residual (i.e., $\boldsymbol{r}_{i j}$ ) represents within team variance in satisfaction. The level-2 residual (i.e., $U_{0 j}$ ) represents any between team variance in satisfaction. By calculating a ratio of the between team variance divided by the total variance in satisfaction, HLM provides information on the percentage of the total variance in satisfaction residing both within and between virtual teams (cf. Hofmann 1997).

In addition to the ability to estimate variance components at multiple levels of analysis (i.e., hypothesis 1), HLM is also able to test the effects of multiple independent variables at each level. This feature is used to test hypothesis 2:

Level-1: Satisfaction $_{i j}=\beta_{0 j}+\beta_{1 j}$ Communication Effectiveness $_{i j}+r_{i j}$

Level-2: $\quad \beta_{0 j}=\gamma_{00}+U_{0 j}$

$$
\beta_{1 j}=\gamma_{10}+U_{1 j}
$$

Hypothesis 3 posits that team coordination has a main affect on individual satisfaction (above and beyond perceived communication effectiveness). This is tested by adding a measure of team coordination at level-2 to predict team satisfaction intercepts $\left(\boldsymbol{\beta}_{0_{j}}\right)$ :

Level-1: Satisfaction $_{i j}=\beta_{0 j}+\beta_{1 j}\left(\right.$ Communication Effectiveness $\left._{i j}\right)+r_{i j}$

Level-2: $\beta_{0 j}=\gamma_{00}+\gamma_{01}\left(\right.$ Team Coordination $\left.{ }_{j}\right)+U_{0 j}$

$$
\beta_{1 j}=\gamma_{10}+U_{1 j}
$$

For each level-2 parameter, HLM provides a $t$-test of statistical significance (i.e., $\gamma_{01}$ ). A statistically significant $t$-test for $\gamma_{01}$ indicates a main effect of team coordination on satisfaction. It is worth noting that when using HLM, variable "centering" affects substantive conclusions that can be drawn from empirical tests 
(Hofmann and Gavin 1998). To control for level-1 variables, they are "centered" around their grand means (Hofmann and Gavin 1998). For example, when testing hypothesis 3 , the level-1 variable that measures communication effectiveness (e.g., $\beta_{1 j}$ Communication Effectivenessij) is modeled by subtracting the grand mean communication effectiveness from the individual's communication effectiveness so that the level-1 variable is now modeled as $\beta_{1 j}$ (Communication Effectivenessij Communication Effectiveness.) where Communication Effectiveness. represents the grand mean of communication effectiveness.

Hypotheses 4 posits a moderating effect of communication quantity:

Level-1: Satisfaction $_{i j}=\beta_{0 j}+\beta_{1 j}($ Communication Effectivenessij $)+r_{i j}$

Level-2: $\quad \beta_{0 j}=\gamma_{00}+\gamma_{01}$ (Communication Quantityj) $+U_{0 j}$ $\beta_{1 j}=\gamma_{10}+\gamma_{11}$ (Communication Quantityj) $+U_{1 j}$

The prediction of $\beta_{1 j}$ by the level-2 variable results in an interaction term that estimates the cross-level interaction. When testing for level-2 moderation, level-1 variables are "centered" around their group (i.e., team) means.

\section{RESULTS AND DISCUSSION}

Analyses were conducted with the HLM 5.0 statistical package (Raudenbush, Bryk and Congdon 2000). We first conduct a variance decomposition by examining a null model with no predictors. The $\chi^{2}$ test for the amount of variation in the changes in satisfaction between-teams is significant $\left(\chi^{2}=133.6 ; p<.001\right)$, providing strong support for hypothesis 1 . Specifically, $70.21 \%$ of the variance in satisfaction exists within teams and $29.79 \%$ exists between teams.

According to hypothesis 2 perceived communication effectiveness is positively related to individual satisfaction. HLM tests this hypothesis in two ways. First, like regression, HLM provides a "fixed effect" coefficient for each parameter tested. This coefficient is significant $(t=7.637 ; p<.001)$. Second, HLM provides a deviance statistic for each model estimated. Comparison to the null model, and an indication of the improvement in explanatory power of the model, is accomplished via a $\chi^{2}$ difference test. This test is highly significant $\left(\Delta \chi^{2}{ }_{3}=53.46 ; \mathrm{p}<.001\right)$ providing support for hypothesis 2 .

Hypothesis 3 posits that team coordination has a significantly impact on individual satisfaction, after controlling for the effect of perceived communication effectiveness. Hypothesis 3 is supported $(t=8.101 ; p<.001)$, and the $\chi^{2}$ test of the deviance statistic shows a significant improvement in the model's explanatory power $\left(\Delta \chi_{1}^{2}=47.01 ; p<.001\right)$.

Finally, hypothesis 4 posits that a team communication quantity moderates the effects of perceived communication effectiveness on individual satisfaction. This test was not significant as noted by the coefficient $(t=-1.334 ; p<.189)$ and $\chi^{2}$ test of the deviance statistic $\left(\Delta \chi_{2}^{2}=1.751 ; p>.5\right)$.

Our data provides support for three of the four research hypotheses. Our results provide empirical evidence for the proposition that individual characteristics are the primary determinant of satisfaction with the virtual team experience. Considerable research should therefore focus on developing profiles of effective virtual team members. Selection of team members should be a primary concern of managers charged with creating and managing virtual teams. 
A considerable amount of variance in individual satisfaction with the virtual team experience was detected between teams, indicating that contextual variables account for almost $30 \%$ of the variance. These results demonstrate the value of a multilevel approach to the study of virtual teams. They also suggest that managers have the opportunity to influence individual satisfaction by shaping the context in which team members interact. Our results demonstrate that team coordination is an important contextual variable. These results are in line with recent case studies showing that effective teams use very intense face-to-face coordination meetings to reduce ambiguity and provide the stability necessary for disperse team members to work efficiently as part of the team (Maznevski and Chudoba 2000). When face-toface meetings are not feasible though, virtual teams must find alternative ways to achieve high coordination. We believe that HLM holds great potential as a tool to help IS researchers develop and tests multilevel theories, and we hope that our study will encourage future research to engage in this promising line of work. While multilevel analysis may involve greater complexity than traditional approaches, we believe that the payoffs of this approach are commensurate to the increasing difficulty.

\section{REFERENCES}

1. Bryk, A. and Raudenbush, S.W. Hierarchical Linear Models: Applications and Data Analysis Strategy. Sage Publications, Newberry Park, CA, 1992.

2. DeSanctis, G. and Poole, M.S. Transitions in teamwork in new organizational forms. Advances in Group Processes, 1997, 14: 157-176.

3. Duarte, D.L. and Snyder, N.T. Mastering Virtual Teams: Strategies, Tools, and Techniques that Succeed, Jossey-Bass Publishers, San Francisco, CA, 1999.

4. Furst, S., Blackburn, R and Rosen, B. Virtual teams: A proposed research agenda. Information Systems Journal, 1999, 9: 249-269.

5. Galegher, J. and Kraut, R.E. Computer-mediated communication for intellectual teamwork: an experiment in group writing. Information Systems Research, 1994, 5: 110-138.

6. Guzzo, R.A. and Dickson, M.W. Teams in organizations: recent research on performance and effectiveness. Annual Review of Psychology, 1996, 47: 307-338.

7. Hackman, J.R. Group influences on individuals in organizations. In: Handbook of Industrial and Organizational Psychology, Dunnette, M.D. and Hough, L.M. (eds.), Consulting Psychologists Press, Palo Alto, CA, 1992.

8. Hofmann, DA. An overview of the logic and rationale of hierarchical linear models. Journal of Management, 1997, 23: 723-744.

9. Hofmann, DA., and Gavin, MB. Centering decisions in hierarchical linear models: Implications for research in organizations. Journal of Management, 1998, 24: 623-641.

10. House, R. Rousseau, D.A. and M. Thomas-Hunt. The meso-paradigm: A framework for the intergration of micro and macro organizational behavior. Research in Organizational Behavior, 1995, 17: 71-114.

11. Jarvenpaa, S. Knoll, K. and Leidner, D. Is anybody out there? Antecedents of trust in global virtual teams. Journal of Management Information Systems, 1998, 14: 29 - 64.

12. Jarvenpaa, S. and Ives, B. The global network organization of the future. Journal of Management Information Systems, 1994, 10: 25 - 58.

13. Jarvenpaa, S. and Leidner, D. Communication and trust in global virtual teams. Organization Science, 1999, 10: 791- 815.

14. Lipnack, J. and Stamps, J. Virtual Teams: Reaching Across Space, Time, and Organizations with Technology. John Wiley and Sons, Inc, 1997.

15. Maznevski, M.L. and Chudoba, K.M. (Forthcoming) Bridging space over time: Global virtual team dynamics and effectiveness. Organization Science.

16. Piccoli, G. and Ives, B. Virtual teams: Swifts trust and the unintended effects of behavior control. Working Paper, Cornell University, Ithaca, NY, 2001. 
17. Pinto, M.B, Pinto, J.K. and Prescott, J.E. Antecedents and consequences of project team crossfunctional cooperation. Management Science, 1993, 39: 1281-1297.

18. Raudenbush, S.W., Bryk, A.S., Congdon, R.T. Jr. HLM 5 for Windows. Lincolnwood, IL: Scientific Software International, 2000.

19. Rousseau, D.M. Issues of level in organizational research: A multi-level and cross-level perspective. In Cummings, L.L. and Staw, B.M. (Eds.) Research in Organizational Behavior. JAI Press, Greenwich, CT, 1985, 7: 1-37.

20. Townsend, A., DeMarie, S. and Hendrickson, A. Virtual teams: technology and the workplace of the future. Academy of Management Executive, 1998, 12: 17-29.

21. Walther, J. Relational aspects of computer-mediated communication: experimental observations over time. Organization Science, 1995, 6: 186-203. 